\title{
Interactive comment on "Salinity-depending carbon and nitrogen uptake of two intertidal foraminifera (Ammonia tepida and Haynesina germanica)" by Michael Lintner et al.
}

Anonymous Referee \#2

Received and published: 19 February 2020

General comments:

The manuscript submitted by Lintner et al. describes the results of salinity-depending feeding experiments with the two most common foraminiferal species in the mud flats Ammonia tepida and Haynesina germanica. As far as I know, the linking between food uptake and salinity has rarely been assessed by other authors and therefore, the new findings of the authors of this article contribute to a better understanding of the physiological behaviour of foraminifers, which could potentially support proxy applications. Generally, the manuscript is well structured, clearly written and I would recommend publishing the manuscript after reassess some minor points/ comments. 
Main point:

Line 93: How did you know that the foraminifera where alive before and after the experiment (e.g. Pseudopodial activity, crawling test, maybe some kind of staining living cells?)? It would be nice if you could go more into detail! How many foraminifera did survive the experiment? Following my culturing experience, it never happens that all specimens survive. Do you see any differences in survival rates between the different salinities?

General Questions concerning culturing method:

1: Have you done any water exchange during the 14 day culturing period?

2: Have you measured or monitored the oxygen content of the water?

3: How was counteracted against evaporation? By adding distilled water? How much evaporation occurred over the day? Have you closed the culturing vessels with a lid or something?

4: Have you measured the $\mathrm{pH}$ ?

Specific comments:

Line 91: What kind of water have you used for wet-sieving? Artificial seawater, water from the location?

Line 94 and 104: Why have you decided to culture under such a high temperature? Because of the highest food uptake rates mentioned in Wukovits et al. 2017? The annual mean temperature of the water is definitely much lower and especially in spring when the highest abundance of food is given temperatures are lower.

Line 121: What was the pore size of the filter?

Printer-friendly version

Line 125: Have you suspended the food in artificial water or anything else before adding? 
Line 126: What do you mean with "untreated"? Are the foraminifera not fed at all in the same setting of the experiment or are they directly picked from the stock culture?

Line 141: Is it possible that residue of clay minerals from the original sediment where still in or around the foraminifera?

Line 377: Furthermore,

Line 400: The situation does only correspond to the conditions in your experiment in terms of food but not in terms of temperature. The temperature in spring will be much lower.

Interactive comment on Biogeosciences Discuss., https://doi.org/10.5194/bg-2019-359, 2019. 